\title{
INTRODUCTION
}

\section{Winners of the ERS Annual Awards 2007}

\author{
V.C. Moore and P.S. Burge
}

$\mathbf{T}$ he European Respiratory Review is delighted to publish the second half of the articles from the winners of the European Respiratory Society Annual Awards 2007. The awardees were invited to include the background to their work, how they thought it might be important to respiratory medicine, the aims of the team in which they work and, finally, to include their award-winning abstract.

This second section begins with Professor Urs Frey, who won the Romain Pauwels Research Award for his work entitled "Asthma as a nonlinear complex dynamic system: a novel approach to understand the temporal behaviour of chronic asthma and its response to $\beta$-agonists" (page 67). By using mathematical methods, he has found that it is possible to calculate the probability or risk that given the current peak expiratory flow (PEF) value, a severe episode of asthma will occur within any time period. Professor Frey is Head of the Division of Paediatric Respiratory Medicine at the University Children's Hospital in Bern, Switzerland.

The research interests of Rodrigo Andres Floto have focused on understanding the basic mechanisms of receptor control of macrophage and dendritic cell function associated with lung infection and autoimmune lung disease. For the Maurizo Vignola Award (page 70), he submitted a paper which examined how dendritic cells are stimulated by mycobacterial heat shock protein through its action on the HIV co-receptor CCR5.

Martina Klein presented research entitled "Prevention of pulmonary vascular and myocardial remodeling by the combined tyrosine and serine-/threonine kinase inhibitor, sorafenib, in pulmonary hypertension and right heart failure" (page 72), which won the François Brenot Award. Her work in pre-clinical cardiology research at Bayer Schering Pharma (Wuppertal, Germany) focuses on pulmonary vascular and myocardial remodelling, as well as the validation and discovery of new drugs for pulmonary hypertension and heart failure.

Two awards were presented to investigators whose research related to tuberculosis (TB). Professor Roumiana Markova's research entitled,
"Monitoring efficacy of anti-TB therapy by using the QuantiFERON-TB Gold In Tube test" (page 74) found that the Gold QFT In tube assay was reduced in all patients 8 months after starting anti-TB treatment, and became negative in 17 out of 30 patients. She works as an immunologist in the Dept of Immunology and Allergy of the National Centre of Infectious and Parasitic Diseases (Sofia, Bulgaria). Agnes Csanadi works in the Dept of Medical Microbiology and Immunobiology at the University of Szeged (Szeged, Hungary). The department in which she works carries out research into infectious diseases, host-pathogen interactions and virulence factors. The primary focus of her work is the characterisation of mycobacteria RNase E/G homologues. Her abstract entitled "Towards new antituberculotic targets: biochemical characterisation of mycobacterial RNase E/G" (page 76) showed that RNase E/G can be used as a promising target for antimicrobial drugs, which can be optimised to specifically target pathogenic species.

Fabian Blank presented work entitled "The epithelial integrity is preserved during particle exchange across the epithelium by macrophages and dendritic cells" (page 78). His group found that human blood monocyte dendritic cells and those derived from macrophages express tight junction and adherens junction mRNA and proteins. They also observed particle exchange between the cells. This supports their hypothesis that these cells collaborate as sentinels. Fabian currently works as a postdoctoral researcher at the University of Bern, Bern, Switzerland.

Juliana Monte Real is an MSc graduate student at the Oncology Program, Hospital AC Camargo, São Paulo, Brazil. Her work has centred on the functional characterisation of genes modulated by the pro-inflammatory cytokine tumour necrosis factor- $\alpha$, particularly the investigation of the role of acute phase protein pentraxin 3 (PTX3) in inflammation. This led to her abstract entitled "The role of the acute phase protein PTX3 in the ventilator-induced lung injury" (page 81), in which her research strongly suggested that PTX3 was involved in the pathogenesis of ventilator-induced lung injury.
AFFILIATIONS

Dept of Respiratory Medicine, Birmingham Heartlands Hospital, Birmingham, UK.

CORRESPONDENCE

V.C. Moore

Dept of Respiratory Medicine Birmingham Heartlands Hospital Bordesley Green East Birmingham B9 5SS

UK

Fax: 441217720292

E-mail: v.c.moore@

heartofengland.nhs.uk

\section{STATEMENT OF INTEREST}

P.S. Burge received financial support from the European Respiratory Society (ERS) for attendance and speaking at the ERS Congress. He received an honorarium payable to his research funds for editing the European Respiratory Review. In the 1980s P.S. Burge received a grant from the Health Promotion Trust (a UK government fund indirectly supported by the tobacco industry). V.C. Moore has received money payable to P.S. Burge's research funds for being secretary of the European Respiratory Review. 
Dr Stefano Aliberti's abstract entitled “Impact of neutrophil function on outcomes of community-acquired pneumonia in patients with cancer" (page 83) concluded that physicians should aggressively manage cancer patients with communityacquired pneumonia, regardless of the neutrophil count, as those with and without neutropenia showed no difference in time to reach clinical stability, length of stay in hospital, overall mortality or pneumonia severity. He currently works as a visiting research fellow at the Division of Infectious Diseases, University of Louisville (Louisville, KY, USA).

Annemie Schoonis is a lead nurse for one of the respiratory units of the University Hospitals, Leuven, Belgium. She has formed the Society of Respiratory Nurses in Belgium which meets every year with the Respiratory Physicians Society. In 2006, she submitted three abstracts to the European Respiratory Society on the topic of smoking cessation. In 2007, she submitted her award-winning abstract entitled "Effectiveness of group counselling for smoking in hospital staff" (page 86). She found that this method of support produced a high smoking cessation rate and results in high numbers of thse who have quit remaining smoke-free for the following 2 yrs while still attending the group.

Stephanie MacNeill is a medical statistician within the Dept of Occupational and Environmental Medicine at the Royal Brompton Hospital (London, UK) and at the National Heart and Lung Institute, Imperial College (London). Her abstract formed part of a wider research study assessing the impact of the Oxford Transport Strategy on the health of residents. Her abstract entitled "The Oxford transport strategy: impact of a traffic intervention on PEF and wheeze among children" (page 88) showed that PEF and wheeze improved post-strategy in children receiving treatment for asthma and in socioeconomic classes III-V. The impact was also greater in subjects who lived near the roads where traffic decreased compared with those living where there had been an increase.

Dr Christopher Burton presented "The effect of baseline lung function on the determination of time to bronchiolitis obliterans syndrome" (page 90) and found that there was a significant $\log -\log$ linear relationship between baseline forced expiratory volume in one second and time to the development of bronchiolitis obliterans syndrome (BOS) grades $0 \mathrm{p}$ to 3 $(\mathrm{p}<0.0001)$. Therefore, baseline lung function should be considered in future risk factor evaluations for the development and progression of BOS. His work as a pulmonary medicine research fellow in the Division of Lung Transplantation, Rigshospitalet (Copenhagen, Denmark) has led to the design and implementation of a clinical database and he is now embarking on a PhD.

Bart Vanaudenaerde works in the Pneumonolgy Laboratory at Katholieke Universiteit in Leven, Belgium. His abstract entitled "The Leuven experience with a dichotomy in Bronchiolitis Obliterans Syndrome after lung transplantation revealed by azithromycin" (page 93) found two types of BOS: neutrophilic reversible allograft dysfunction and fibropoliferative BOS. The former reacts to azithromycin therapy whereas the latter does not. This work has led to further investigations of the phenotypes of BOS and possible future changes to its definition.

Catarina Almqvist examined the effects of cumulative house dust mite allergen exposure during the first $5 \mathrm{yrs}$ of life on outcomes at age 5 yrs in Sydney, Australia, a high house dust mite environment, in her abstract, entitled "The bell tolls for the relationship between house dust mite exposure and asthma in childhood" (page 96). She found that there is a bell-shaped dose response between house dust mite levels and sensitisation and asthma. Her PhD thesis included work on cat allergen on clothing and she has since continued her work in environmental risk-factors for asthma and allergic diseases.

Two awards were presented to investigators whose research was related to sleep apnoea. Dr Stijn Verhulst is a fellow in paediatrics at the Dept of Paediatrics, University of Antwerp, Antwerp, Belgium. He has completed a $\mathrm{PhD}$ thesis in sleepdisordered breathing and his abstract entitled "Sleep-disordered breathing: a new risk factor of suspected fatty liver disease in overweight children and adolescents?" (page 99) is the result of ongoing collaborations in this area. His abstract suggested that there is an association between the severity of sleep-disordered breathing and suspected fatty liver disease in this group. $\mathrm{He}$ believes further work needs to be undertaken regarding this association. Dr P. Korczyński presented an abstract entitled "CPAP increases bronchial reactivity in OSAS patients" (page 101). He investigated newly diagnosed obstructive sleep apnoea syndrome patients without infection or chronic illness of the respiratory tract or other conditions that could influence bronchial reactivity. Methacholine challenge was performed before therapy and after 3 weeks of continuous positive airway pressure and showed a significant increase in reactivity. He works as a doctor and lecturer within the Dept of Pneumonology at the Warsaw Medical University, Warsaw, Poland. 